\title{
HISTOPATHOLOGY OF VEINS AFTER INTRAVENOUS LORAZEPAM AND RO 21-3981
}

\author{
Richard R. Pagano, Charles W. Graham, Michael Galligan, \\ James T. Conner, and Ronald L. Katz
}

\section{INTRODUCTION}

DIAZEPAM, a benzodiazepine frequently administered intravenously, is associated with a high incidence of pain on injection and subsequent thrombophlebitis. ${ }^{1}$ To help elucidate this, we recently reported the histological effects of intravenous diazepam using a rat vein model. ${ }^{2}$ The present study extends this model to the evaluation of lorazepam and RO 21-3981, two new benzodiazepines (Figure 1).

\section{Materials AND Methods}

Details of the rat histological model have appeared elsewhere. ${ }^{2}$ Briefly, the saphenous veins were exposed bilaterally in 45 healthy Wistar rats weighing approximately $250 \mathrm{gm}$ and cannulated with 25 -gauge needles. Lorazepam $0.012 \mathrm{mg}$ or<smiles>CCCCN=C(c1ccccc1)c1cc(Cl)ccc1N(C)C(=O)CC</smiles>

DIAZEPAM<smiles>O=C(O)Nc1ccc(Cl)cc1C(=O)NC(=O)c1ccccc1Cl</smiles>

LORAZEPAM<smiles>Cc1ncc2n1-c1ccc(Cl)cc1C(C)C=NC(c1ccccc1F)=NC2</smiles>

RO 21-3981

FIGURE 1. The chemical structure of diazepam, lorazepam, and RO 21-3981.

Richard R. Pagano, M.D., Resident in Anaesthesia; Charles W. Graham, M.D., Ph.D., Resident in Anaesthesia; Michael Galligan, M.D., Resident in Pathology; James T. Conner, M.D., Assistant Professor; Ronald L. Katz, M.D., Professor and Chairman.
$0.2 \mathrm{mg}$, RO $21-3981,0.0375 \mathrm{mg}$ or $0.125 \mathrm{mg}$, propylene glycol $0.4 \mathrm{mg}$ or $2 \mathrm{mg}$, or 0.9 per cent normal saline was infused slowly so that the agent was in contact with the vein wall for five seconds. Subsequently the animals were left undisturbed for 48 hours. The veins were then removed and prepared for histological examination. Light microscopy was performed by two pathologists unaware of the drug given and evidence of inflammatory response in and around the vessel was recorded. Observed alterations were classified: 0 to +++ reflecting degree of inflammation observed.

\section{Results}

Intravenous injection of control 0.9 per cent normal saline did not alter the normal histology of the vascular tissue (Figure 2).

Infusion of lorazepam $0.012 \mathrm{mg}$ resulted in a histological picture similar to saline control; vascular integrity was not altered. In marked contrast, lorazepam $0.2 \mathrm{mg}$ resulted in pronounced vascular inflammation including vessel dilatation, interstitial oedema, and polymorphonuclear leukocyte infiltration with subsequent thrombosis (Figure 3).

The histological alterations observed following intravascular propylene glycol are in Table I. Intravascular thrombosis with intramural poly-

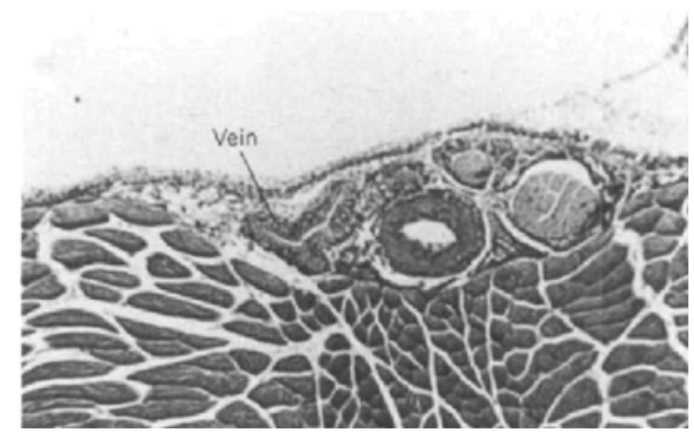

Figure 2. Normal vein following infusion of 0.9 per cent control saline (Haematoxylin and eosin, 150x). 


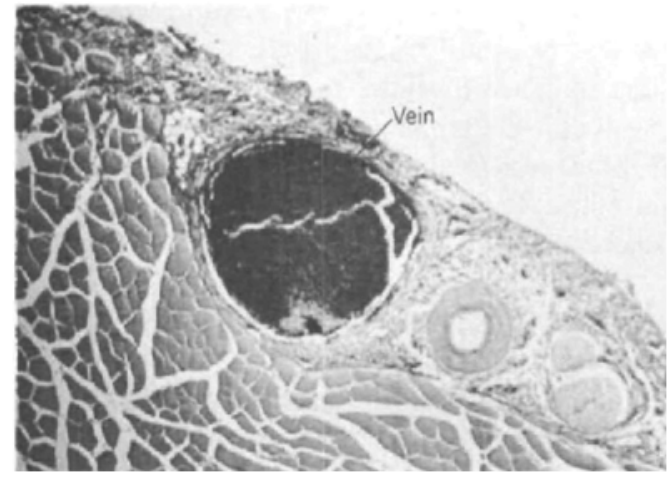

Figure 3. Intravascular inflammatory alterations 48 hours after lorazepam $0.2 \mathrm{mg}$ intravenously. Note dilatation and thrombosis of vein (Haematoxylin and eosin, 150x).

morphonuclear leukocyte infiltration similar to high-dose lorazepam was present.

There was no evidence of vascular pathology with either $0.0375 \mathrm{mg}$ or $0.125 \mathrm{mg}$ of RO 21-3981.

\section{Discussion}

It has been previously demonstrated that there is histological vascular alteration following intra-arterial ${ }^{3}$ and intravenous diazepam ${ }^{2}$ including venous dilatation, stasis, interstitial infiltration, and thrombosis as early as 48 hours after injection. The present study extends these findings by evaluating two new benzodiazepines for similar alterations. These two drugs are of particular interest because lorazepam appears to produce less clinical pain and inflammatory response in intravenous injection than diazepam* while RO 21-3981 by virtue of its water soluble base $\dagger$, may be devoid of any vascular inflammatory effect.

Low dose lorazepam and RO 21-3981 did not result in appreciable intravascular pathology. These doses correspond to $4 \mathrm{mg}$ and $10 \mathrm{mg}$ respectively in a $70 \mathrm{~kg}$ man. In an attempt to delineate a dose response curve, doses five times and 20 times these doses were also evaluated. Lorazepam gave evidence of intravascular damage at high doses, while there was no observable vascular response to high doses of RO 21-3981.

*C.W. Graham, R.R. Pagano, J. Conner, unpublished observation.

† Each ml of RO 21-3981 contains: RO 21-3981 3.5 mg, tartaric acid $4 \mathrm{mg}$, disodium edetate $0.1 \mathrm{mg}$, sodium chloride $7 \mathrm{mg}$, benzyl alcohol $0.01 \mathrm{ml}, \mathrm{NaOH}$ ten per cent q.s. pH $3.3 \pm 0.1$ water for injection q.s. $1.0 \mathrm{ml}$.
TABLE I

The Effect of Lorazepam, RO 21-3981, and PropyLENE GLYCOL ON INTRAVASCULAR INFLAMMATION

\begin{tabular}{lcl}
\hline \hline \multicolumn{1}{c}{ Drug } & $\begin{array}{c}\text { Number } \\
\text { of } \\
\text { animals }\end{array}$ & Response \\
\hline Lorazepam & & \\
$0.012 \mathrm{mg}$ & 8 & 0 \\
$0.2 \mathrm{mg}$ & 9 & +++ \\
RO $21-3981$ & & \\
$0.0375 \mathrm{mg}$ & 9 & 0 \\
$0.125 \mathrm{mg}$ & 9 & 0 \\
Propylene glycol & & \\
$0.4 \mathrm{mg}$ & 7 & +++ \\
$2.0 \mathrm{mg}$ & 3 & ++ to +++ \\
0.9 per cent normal saline & 45 & 0 \\
\hline
\end{tabular}

0 - Normal tissue.

+ - Vascular dilatation and interstitial edema with mild cellular response.

++- Vascular dilatation and interstitial edema with pronounced cellular response.

+++- Marked inflammation with vascular destruction and/or thrombosis.

We have previously speculated that the solvent vehicle* may play an important role in the mechanism responsible for the vascular damage inflicted by diazepam. ${ }^{2}$ All doses of diazepam studied which contained propylene glycol produced vascular damage. In addition, propylene glycol when administered alone consistently caused marked vascular inflammation. The present study lends additional evidence to this hypothesis. When a benzodiazepine preparation without propylene glycol was tested (RO 213981) no histological damage was observed. Furthermore, when a benzodiazepine preparation containing reduced amounts of propylene glycol was evaluated (lorazepam), it was necessary to increase the dosage to produce appreciable vascular pathology. Although propylene glycol may have an important role in this pathogenesis, there may be a critical concentration necessary to produce vascular pathology. Further studies evaluating a dose response effect with propylene glycol are indicated.

*Each $\mathrm{ml}$ of diazepam is compounded with 40 per cent propylene glycol, ten per cent ethyl alcohol. five per cent sodium benzoate and benzoic acid as buffers, and 1.5 per cent benzyl alcohol as preservative. Each $\mathrm{ml}$ of lorazepam is compounded with $0.2 \mathrm{ml}$ benzyl alcohol and $0.18 \mathrm{ml}$ propylethylene glycol in propylene glycol. 


\section{SUMMARY}

A previously established rat model has been utilized to demonstrate that an acute inflammatory response occurs after high intravenous doses of lorazepam. This occurs only with high concentrations of drug equivalent to 20 times the normal clinical dosage in man. In contrast, water soluble RO 21-3981 produces no vascular pathology in any dosage evaluated. It appears that propylene glycol may play a role in the pathogenesis of the intravascular injury observed.

\section{RÉSUMÉ}

Une réaction inflammatoire aigüe a déjà été démontrée chez le rat après injection intraveineuse de lorazepam à fortes doses. Cette réaction n'arrive qu'avec des concentrations élevées équivalant à 20 fois la dose utilisée cliniquement chez l'homme. Par ailleurs, la solu- tion aqueuse de RO 21-3981 s'est avérée non irritante pour les veines à toutes les concentrations étudiées. Il semble que ce soit le propylène glycol utilisé comme préservatif dans la solution de lorazepam (et dans les solutions de diazepam) qui est le responsable des effets irritants vasculaires.

\section{ACKNOWLEDGEMENTS}

The authors wish to thank Roche and Wyeth for supplying RO 21-3981 and lorazepam.

\section{REFERENCES}

1. LANGdon, D.E., HaRlan, J.R., \& Bailey, R.L. Thrombophlebitis with diazepam used intravenously. J.A.M.A. 223: 184 (1973).

2. Graham, C.W., Pagano, R.R., \& Katz, R.L. Thrombophlebitis after intravenous diazepam can it be prevented? Anesth. Analg. 56:409 (1977).

3. KNILL, R.L. \& Evans, D. Pathogenesis of gangrene following intra-arterial injection of drugs: a new hypothesis. Can. Anaes. Soc. J. 22:637 (1975). 